\title{
Contribution to More Patient-Friendly ART Treatment: Efficacy of Continuous Low-Dose GnRH Agonist as the Only Luteal Support-Results of a Prospective, Randomized, Comparative Study
}

\author{
Céline Pirard, ${ }^{1}$ Ernest Loumaye, ${ }^{2}$ Pascale Laurent, ${ }^{1}$ and Christine Wyns ${ }^{1}$ \\ ${ }^{1}$ Department of Gynecology-Andrology, Cliniques Universitaires Saint-Luc, Institut de Recherche Expérimentale et Clinique (IREC), \\ Université Catholique de Louvain, 1200 Brussels, Belgium \\ ${ }^{2}$ ObsEva SA, 1228 Geneva, Switzerland \\ Correspondence should be addressed to Christine Wyns; christine.wyns@uclouvain.be
}

Received 14 December 2014; Accepted 18 March 2015

Academic Editor: Carlo Cappelli

Copyright (C) 2015 Céline Pirard et al. This is an open access article distributed under the Creative Commons Attribution License, which permits unrestricted use, distribution, and reproduction in any medium, provided the original work is properly cited.

\begin{abstract}
Background. The aim of this pilot study was to evaluate intranasal buserelin for luteal phase support and compare its efficacy with standard vaginal progesterone in IVF/ICSI antagonist cycles. Methods. This is a prospective, randomized, open, parallel group study. Forty patients underwent ovarian hyperstimulation with human menopausal gonadotropin under pituitary inhibition with gonadotropin-releasing hormone antagonist, while ovulation trigger and luteal support were achieved using intranasal GnRH agonist (group A). Twenty patients had their cycle downregulated with buserelin and stimulated with hMG, while ovulation trigger was achieved using 10,000 IU human chorionic gonadotropin with luteal support by intravaginal progesterone (group B). Results. No difference was observed in estradiol levels. Progesterone levels on day 5 were significantly lower in group A. However, significantly higher levels of luteinizing hormone were observed in group A during the entire luteal phase. Pregnancy rates (31.4\% versus $22.2 \%)$, implantation rates (22\% versus $15.4 \%)$, and clinical pregnancy rates $(25.7 \%$ versus $16.7 \%)$ were not statistically different between groups, although a trend towards higher rates was observed in group A. No luteal phase lasting less than 10 days was recorded in either group. Conclusion. Intranasal administration of buserelin is effective for providing luteal phase support in IVF/ICSI antagonist protocols.
\end{abstract}

\section{Introduction}

Cycles resulting from controlled ovarian hyperstimulation $(\mathrm{COH})$, when downregulated with gonadotropin-releasing hormone $(\mathrm{GnRH})$ agonist or GnRH antagonist, commonly result in luteal phase deficiency $[1,2]$. This phenomenon is characterized by low progesterone levels, delayed endometrial secretory transformation, and a shortened luteal phase of less than ten days [3], resulting in reduced embryo implantation, lower pregnancy rates, and increased miscarriage rates. For this reason, luteal phase support is a common practice in IVF treatments, as it significantly improves embryo implantation, pregnancy, and delivery rates [2].

Vaginal progesterone with or without estradiol and intramuscular human chorionic gonadotropin (hCG) are the current regimens used for luteal phase support. Since hCG administration is associated with the risk of ovarian hyperstimulation syndrome (OHSS), progesterone is the preferred choice [4].

It was reported that $\mathrm{GnRH}$ agonists administered during the luteal phase in addition to standard luteal phase support improved pregnancy rates in IVF-stimulated cycles [5-14], but the mechanism of this apparently beneficial effect is poorly understood. GnRH agonists may support the corpus luteum by stimulating the secretion of luteinizing hormone (LH) by pituitary gonadotroph cells, by acting directly on the endometrium through locally expressed receptors, or by their direct effect on the embryo $[6,7]$.

The question as to whether GnRH agonist alone is able to efficiently support the luteal phase nevertheless remains. 


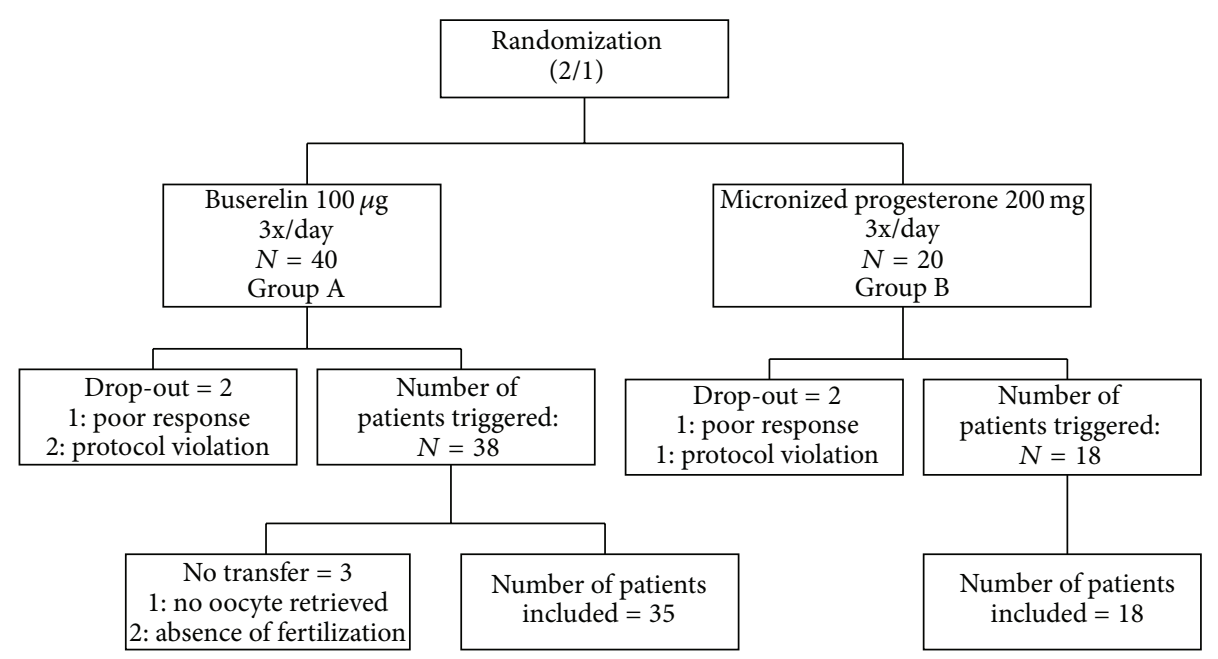

FIGURE 1: Randomization and allocation of patients to the two groups. In group A, ovulation was triggered with buserelin and the luteal phase was also supported by buserelin. In group B, ovulation was triggered with hCG and the luteal phase was supported with vaginal micronized progesterone.

We previously reported that, in patients undergoing $\mathrm{COH}$, intranasal (IN) administration of buserelin for 15 days is able to trigger final follicular maturation and has a marked, dose-related effect on the luteal phase [15]. This observation led to the conclusion that the optimal dose of buserelin for luteal support in an antagonist protocol is $100 \mu \mathrm{g} 3$ times per day.

To further analyze the potential benefits of this new protocol, our study objective was to assess the efficacy of luteal phase GnRH agonist administration in cycles where ovulation was triggered by $\mathrm{GnRH}$ agonist and compare it with a standard protocol using hCG to trigger ovulation, followed by intravaginal progesterone as luteal support. To the best of our knowledge, this is the first randomized controlled trial using GnRH agonist as the only luteal phase support.

\section{Materials and Methods}

2.1. Study Design and Patient Randomization. In order to study the effect of IN administration of GnRH agonist to trigger and support the luteal phase, we initiated a single-center, prospective, randomized, open, parallel group study. We were looking to compare this method in patients undergoing IVF/ICSI after stimulation of multiple follicular development with human menopausal gonadotropin (hMG). Inclusion criteria were the age between 18 and 39 and BMI $\geq 18$ but $\leq 35$, while exclusion criteria were a history of poor response, systemic disease (diabetes, severe migraine, hepatic, renal, or cardiovascular disease, and corticodependent asthma), and ovarian cysts $\geq 11 \mathrm{~mm}$.

Computer-generated randomization was applied (2/1; group A/B). Treatment allocation instructions were placed in individually sealed envelopes to be opened at the center in chronological order on the day of signing the informed consent form.

In study group A, GnRH agonist (buserelin) was administered IN to trigger final follicular maturation and support the luteal phase. In control group B, hCG was administered to trigger final follicular maturation and vaginal progesterone to support the luteal phase.

The primary end-point was the comparison of pregnancy rates between the two groups.

The study protocol and informed consent form were approved by the institution's ethics committee.

\subsection{Ovarian Stimulation Protocol and Treatment Groups.} Sixty patients with infertility factors indicating IVF or ICSI were enrolled in this study, as shown in Figure 1.

In study group $\mathrm{A}, 40$ patients underwent $\mathrm{COH}$ using hMG (Menopur, Ferring, Brussels, Belgium) at a dose ranging from 150 to $450 \mathrm{IU}$ daily. When the leading follicle reached a mean diameter of $14 \mathrm{~mm}$, daily administration of $0.25 \mathrm{mg} \mathrm{GnRH}$ antagonist (Orgalutran; MSD, Brussels, Belgium) was initiated every evening up to the day before ovulation trigger.

When patients met the criteria for ovulation trigger (at least 3 follicles $>17 \mathrm{~mm}$ ), they received $200 \mu \mathrm{g}$ of IN buserelin (Suprefact; Aventis, Brussels, Belgium), followed by $100 \mu \mathrm{g}$ IN buserelin three times a day for luteal support starting the next day, as previously published by our team [15]. This was continued for a maximum of 16 days until the day of the pregnancy test, whether or not it proved positive.

In control group B, 20 patients had a cycle downregulated with $\mathrm{GnRH}$ agonist and stimulated with hMG at a dose ranging from 150 to $450 \mathrm{IU}$ daily. When they met the criteria for ovulation trigger (at least 3 follicles $>17 \mathrm{~mm}$ ), they were given 10,000 IU subcutaneous hCG (Pregnyl; MSD, Brussels, Belgium), followed by $200 \mathrm{mg}$ vaginal progesterone three times a day (Utrogestan; Goodlife pharma, Lelystad, Netherlands), starting on the day of oocyte pick-up for luteal support. Progesterone was administered up to day 16 (day of the pregnancy test). If the pregnancy test proved positive, progesterone administration was continued up to week 12 of pregnancy, which is a common practice in our center. 
TABLE 1: Patient demographics and stimulation parameters (mean \pm SD).

\begin{tabular}{lccc}
\hline & Group A & Group B \\
& (buserelin 3x/day) & $n=35$ & (micronized progesterone 3x/day) \\
& $n=18$ & \\
\hline Age (years) & $32 \pm 4.4$ & $33 \pm 4.5$ & $\mathrm{NS}$ \\
Range & $2 \pm 1.1$ & $2 \pm 1.3$ & $\mathrm{NS}$ \\
HMG (IU) & $2526 \pm 988$ & $2614 \pm 1077$ & $\mathrm{NS}$ \\
Day of trigger (=D0) & $12.7 \pm 2.7$ & $12.9 \pm 2.6$ & $\mathrm{NS}$ \\
Estradiol D0 (pg/mL) & $2960 \pm 1068$ & $2929 \pm 1439$ & $\mathrm{NS}$ \\
Progesterone D0 $(\mathrm{ng} / \mathrm{mL})$ & $0.9 \pm 0.4$ & $1 \pm 0.4$ & $\mathrm{NS}$ \\
Endometrial thickness D0 $(\mathrm{mm})$ & $9.8 \pm 2.1$ & $9.0 \pm 3.0$ & $\mathrm{NS}$ \\
\hline
\end{tabular}

Pregnancy was diagnosed by measuring serum hCG levels on day 14 of the luteal phase (day of first hCG/buserelin administration $=\mathrm{D} 0)$. $\mathrm{A}$ pregnancy test was considered positive if an increase in serum hCG was observed after a first test showing at least $>10 \mathrm{mIU} / \mathrm{mL}$. The implantation rate was calculated as the number of gestational sacs divided by the number of transferred embryos.

Clinical pregnancy was defined as the presence of an intrauterine gestational sac with a positive heartbeat visualized by vaginal ultrasound.

The duration of the luteal phase was calculated from day 1 (the first day after ovulation trigger) up to the day before menstruation commenced.

IVF laboratory culture conditions were the same as those previously described [15].

All embryos were transferred on day 3.

2.3. Hormone Assays. Serum estradiol, serum progesterone, and serum LH concentrations were monitored on D0 (day of ovulation trigger), D2, D5, D9, and D14. Hormone levels were determined with commercially available kits routinely used in our accredited clinical center's central laboratory. Estradiol, progesterone, and LH were assayed using the Elecsys 2010 system (Roche Diagnostics GmbH, 68298 Mannheim, Germany). The E2 intra-assay coefficient of variation (CV) was $<6 \%$ and the interassay $\mathrm{CV}$ was $<6 \%$; the $\mathrm{P} 4$ intraassay $\mathrm{CV}$ was $<3 \%$ and the interassay $\mathrm{CV}$ was $<6 \%$; the $\mathrm{LH}$ intra-assay $\mathrm{CV}$ was $<2 \%$ and the interassay $\mathrm{CV}$ was $<5 \%$. Serum hCG was assayed using the Beckman-Coulter system (Anablis, Namur, Belgium), yielding an intra-assay CV of $<2 \%$ for a value $<5 \mathrm{mIU} / \mathrm{mL}$ and an interassay $\mathrm{CV}$ of $<12 \%$.

2.4. Statistical Analysis. Descriptive quantitative statistics (mean and SD) were calculated for demographic and ovarian stimulation status parameters, IVF/ICSI and embryo transfer parameters, and luteal phase duration. Comparison between groups was done using the student $t$-test. $P<0.05$ was considered statistically significant.

\section{Results}

Sixty patients were randomized at a ratio of 2/1 (group A/group B). Five patients dropped out of group $A$ and two from group B, leaving 53 patients eligible for analysis. Patient groups did not differ in their basic demographic characteristics, and $\mathrm{COH}$ parameters were also comparable (Table 1).

The mean number of retrieved oocytes, cleaved embryos, and transferred embryos did not show any statistical difference. Embryo transfer was performed in both groups, with a mean number of 1.4 embryos per transfer (Table 2). Furthermore, the mean number of good quality embryos was similar in both groups.

In group $A, 11$ positive pregnancy tests were recorded during the study. Nine pregnancies were confirmed as clinical pregnancies, 7 of which were singleton and 2 were twin pregnancies. One pregnancy ended in miscarriage at 9 weeks and one was terminated because of spina bifida and another for severe preeclampsia. Eight healthy babies were born after 37 weeks of pregnancy.

In group $\mathrm{B}, 4$ positive pregnancy tests were recorded during the study. Three pregnancies were confirmed as clinical pregnancies, 2 of which were singleton and one was a twin pregnancy. Four healthy babies were born after 37 weeks of pregnancy.

While similar numbers of retrieved oocytes and transferred embryos were found between groups, patients in group A showed a tendency towards a higher pregnancy rate $(31.4 \%$ versus $22.2 \%$ ), implantation rate (22\% versus $15.4 \%)$, and clinical pregnancy rate ( $25.7 \%$ versus $16.7 \%)$, despite the fact there is no statistically significant difference (Table 2).

Endometrial thickness on D9 of the luteal phase was also similar in both groups $(10.7 \pm 3 \mathrm{~mm}$ versus $10.5 \pm 4.4 \mathrm{~mm})$.

Hormone levels during the luteal phase are shown in Figure 2. The progesterone profile during the luteal phase was similar in both groups, except on D5, where it was significantly higher $(P<0.05)$ in group B $(91.4 \pm 38.8 \mathrm{ng} / \mathrm{mL})$ than in group A $(61.7 \pm 36.9 \mathrm{ng} / \mathrm{mL})$ (Figure $2(\mathrm{a}))$. Estradiol levels were comparable during the entire luteal phase (Figure 2(b)). By contrast, mean serum LH levels were significantly higher throughout the luteal phase in group A than in group B (where serum LH levels were below the limit of detection $(<0.1 \mathrm{IU} / \mathrm{L})$ in most samples taken between D2 and D9) (Figure 2(c)).

The duration of the luteal phase assessed in patients who did not become pregnant ranged between 11 and 21 days in group A (mean $13.8 \pm 2.3$ ) and between 11 and 19 days in group 
TABLE 2: IVF/ICSI cycle outcomes (mean \pm SD).

\begin{tabular}{|c|c|c|c|}
\hline & $\begin{array}{c}\text { Group A } \\
\text { (buserelin 3x/day) } \\
n=35\end{array}$ & $\begin{array}{c}\text { Group B } \\
\text { (micronized progesterone 3x/day) } \\
n=18\end{array}$ & $P$ \\
\hline Retrieved oocytes $(n)$ & $10.1 \pm 4.1$ & $10.7 \pm 5.9$ & NS \\
\hline Cleaved embryos $(n)$ & $5.8 \pm 2.7$ & $6.0 \pm 3.2$ & NS \\
\hline Transferred embryos $(n)$ & $1.4 \pm 0.5$ & $1.4 \pm 0.5$ & NS \\
\hline Pregnancy rate/transfer & $\begin{array}{c}11 / 35 \\
31.4 \%\end{array}$ & $\begin{array}{c}4 / 18 \\
22.2 \%\end{array}$ & NS \\
\hline Clinical pregnancy rate & $\begin{array}{c}9 / 35 \\
25.7 \%\end{array}$ & $\begin{array}{c}3 / 18 \\
16.7 \%\end{array}$ & NS \\
\hline Implantation rate & $\begin{array}{l}11 / 50 \\
22 \%\end{array}$ & $\begin{array}{c}4 / 26 \\
15.4 \% \\
\end{array}$ & NS \\
\hline
\end{tabular}

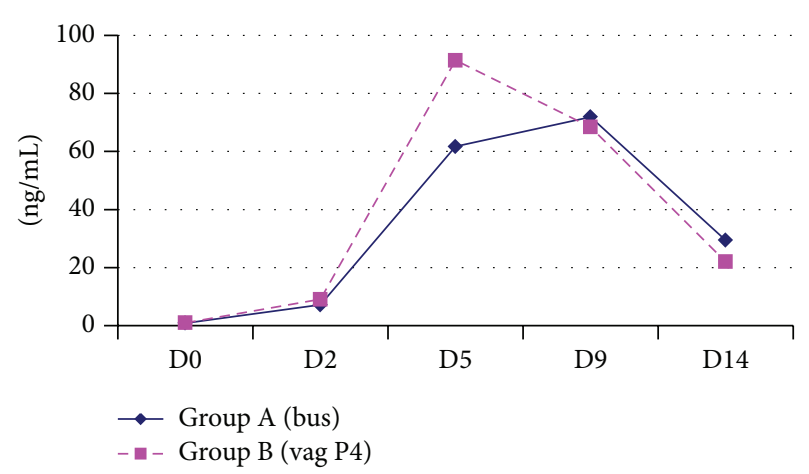

(a) Mean serum P4 levels

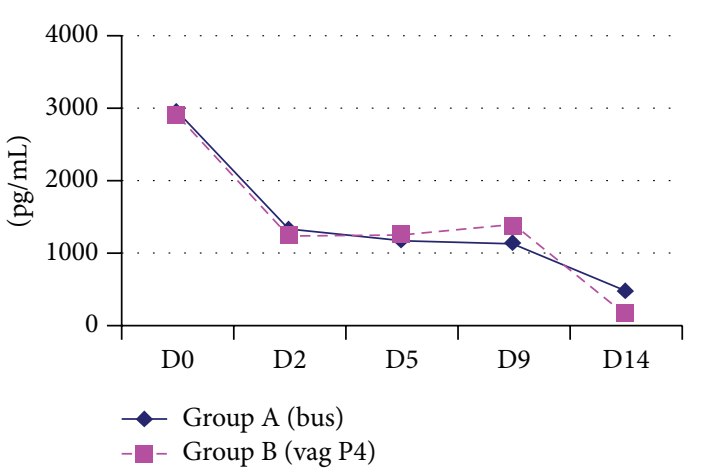

(b) Mean serum E2 levels

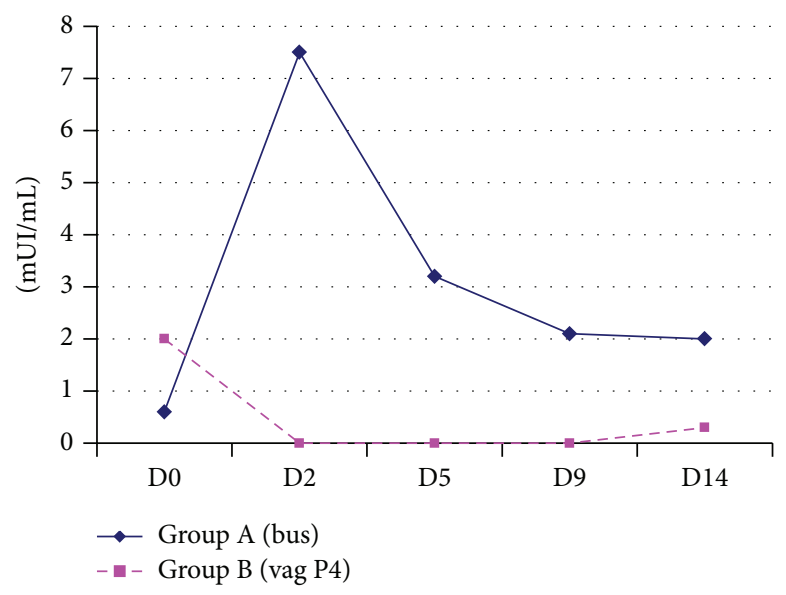

(c) Mean serum LH levels

FIGURE 2: Hormone levels during the luteal phase on D0 (day of ovulation trigger), D2, D5, D9, and D14. (a) Mean progesterone levels. (b) Mean estradiol levels. (c) Mean LH levels.

B (mean $14.7 \pm 2.7)$. No luteal phase lasting less than 10 days was recorded in either group.

Buserelin treatment was well tolerated by all patients. There was no further drop-out, and no significant adverse events were reported in terms of local or systemic tolerance. No OHSS requiring hospitalization was recorded.

\section{Discussion}

During the menstrual cycle, a normal luteal phase is required for embryo implantation and evolution of pregnancy. The luteal phase is the result of intermittent stimulation of the corpus luteum by pituitary LH. During the luteal phase, pituitary LH pulses are of low frequency, leading to extended episodes of progesterone secretion at a rate of 3-5 per 24 hours [20]. Luteal phase deficiency is a common feature of cycles resulting from $\mathrm{COH}$ [21] including $\mathrm{GnRH}$ antagonisttreated cycles [22-24]. It is characterized by premature regression of the corpus luteum, leading to a shortened luteal phase ( $<10$ days), low serum progesterone levels, and delayed secretory transformation of the endometrium [25]. Consequences of luteal phase deficiency are reduced embryo 
implantation rates, lower pregnancy rates, and increased miscarriage rates when pregnancy is established [2]. Besides standard luteal phase support with progesterone, various other methods have also been studied, including use of low-dose hCG [26-30], hCG according to ovarian response to stimulation [31], recombinant LH [32], and intensive progesterone and estradiol administration [33-35]. Because inadvertent administration of $\mathrm{GnRH}$ agonist does not appear to compromise pregnancy outcome [36], a number of studies have also investigated the potential benefits of using $\mathrm{GnRH}$ agonist for luteal phase support in IVF/ICSI cycles (Tables 3 and 4). The findings are somewhat contradictory, however, with studies identifying a positive $[5,7,9,10,13]$, absent $[12,14,16]$, or negative $[17,19]$ impact on outcome in long agonist stimulation protocols. Although the number of studies investigating antagonist protocols is smaller, a similar positive influence on implantation and pregnancy rates has been reported in most of these [7, 11, 13, 15]. Protocols of $\mathrm{GnRH}$ agonist administration vary, with intermittent single, double, or multiple doses or continuous administration during the luteal phase. It is noteworthy that all studies use GnRH agonist in combination with other luteal phase support methods previously mentioned. No comparison can therefore be made between our results and those in the reported literature. In our previous dose-finding study on the use of GnRH agonist for luteal support, we demonstrated that buserelin is able to induce final follicular maturation, trigger ovulation, and support alone the luteal phase when administered at the appropriate dose [15].

Luteal phase support after $\mathrm{COH}$ is even more important when triggering with $\mathrm{GnRH}$ agonists. Previous randomized controlled trials $[37,38]$ found that the use of $\mathrm{GnRH}$ agonist to trigger ovulation was associated with negative clinical results, namely, low implantation and clinical pregnancy rates and high rates of early pregnancy loss, presumably related to luteal phase insufficiency despite standard supplementation with progesterone and estradiol [27]. Only intensive progesterone and estradiol support [33-35] and hCG [2631] or recombinant $\mathrm{LH}$ [32] were able to normalize the luteal phase after $\mathrm{GnRH}$ agonist administration for ovulation trigger. Finally, in a very recent Cochrane review, Youssef et al. [39] reported that, in women undergoing fresh autologous IVF/ICSI cycles, GnRH agonists were associated with a lower ongoing pregnancy rate than that obtained with hCG $(\mathrm{OR}=$ 0.70; 95\% CI: 0.54 to 0.91$)$. However, the effect was dependent on the type of luteal support provided. The higher pregnancy rate in the hCG trigger group applied only to the GnRH agonist trigger group that received luteal support without $\mathrm{LH}$ activity $(\mathrm{OR}=0.36,95 \% \mathrm{CI}: 0.21$ to 0.62$)$ [39].

Studies showing that implantation rates remain normal in oocyte recipients and frozen-thawed cycles with embryos issuing from protocols with $\mathrm{GnRH}$ agonist trigger [40, 41] confirm that a deficient luteal phase is the main problem leading to reduced outcomes.

In our study, similar outcome parameters were obtained when GnRH agonist was used to trigger ovulation, demonstrating that GnRH agonist (IN buserelin) is able to adequately support the luteal phase. Indeed, the implantation potential of our embryos did not appear to be hampered compared to the standard protocol using hCG for ovulation trigger and vaginal progesterone as luteal support. Furthermore, an additional study conducted in our department, in which hCG was used to trigger ovulation and GnRH agonist (without any other supplementation) to support the luteal phase, found similar pregnancy rates (data not shown) and hence corroborates the current study.

The beneficial effect of GnRH agonist during the luteal phase may be linked to its impact on the embryo or a direct or indirect effect on the endometrium. Indeed, $\mathrm{GnRH}$ receptors have been shown to be present in preimplantation human embryos in the luteal phase at both the mRNA and protein levels $[42,43]$, and different observations support the hypothesis that $\mathrm{GnRH}$ agonist exerts a direct beneficial effect on embryos [6, 7]. Animal experiments suggest that GnRH agonists can enhance the in vitro development of embryos $[42,44-46]$. In addition, GnRH agonists appear to have a regulatory impact on the synthesis and secretion of hCG by preimplanted embryos and the placenta $[7,47,48]$.

Direct action on uterine tissue may also be responsible for the effects of GnRH agonists in the luteal phase. The presence of a GnRH receptor showing a dynamic pattern (more intense in the luteal phase) was demonstrated in human endometrium, both in the epithelium and stroma, providing evidence that $\mathrm{GnRH}$ may play a key role as a molecular autocrine-paracrine regulator in embryonicendometrial interactions during early implantation [49-51].

The corpus luteum is another possible $\mathrm{GnRH}$ agonist target, though it is questionable whether such action would occur through the secretion of pituitary hormones or by direct action in the ovary [52]. In cycles with GnRH antagonists, it is speculated that the stimulation of corpus luteum activity by $\mathrm{GnRH}$ agonist may result from the stimulation of LH secretion, given that, despite the blockade, the pituitary gland remains responsive to $\mathrm{GnRH}$ or GnRH agonist [11].

In our study, we found completely different $\mathrm{LH}$ profiles during the luteal phase between the two groups, with significantly higher LH levels when GnRH agonist was administered for luteal support. Although preliminary, our data suggest that maintaining LH secretion throughout the luteal phase by repeated administration of GnRH agonist could overcome the drawbacks of GnRH agonist-induced final follicular maturation followed by standard luteal support.

Besides LH-mediated stimulation of steroid production by the corpus luteum, LH activity could also have an impact on the endometrium through $\mathrm{LH}$ receptors expressed in the endometrium [53-55] or by promoting expression and secretion of relaxin [56], angiogenic and growth factors, and cytokines involved in implantation [57].

In conclusion, our study confirms that GnRH agonist is able to trigger ovulation and support the luteal phase in antagonist IVF cycles, showing comparable efficacy to the standard protocol. Furthermore, this new approach has several advantages over other forms of luteal support in terms of convenience for the patient, because nasal administration is easily done anywhere, is not painful, and does not require the help of a nurse. Since GnRH agonist was the only drug administered for luteal support, compared to other protocols that add GnRH agonist to their classic luteal support, 


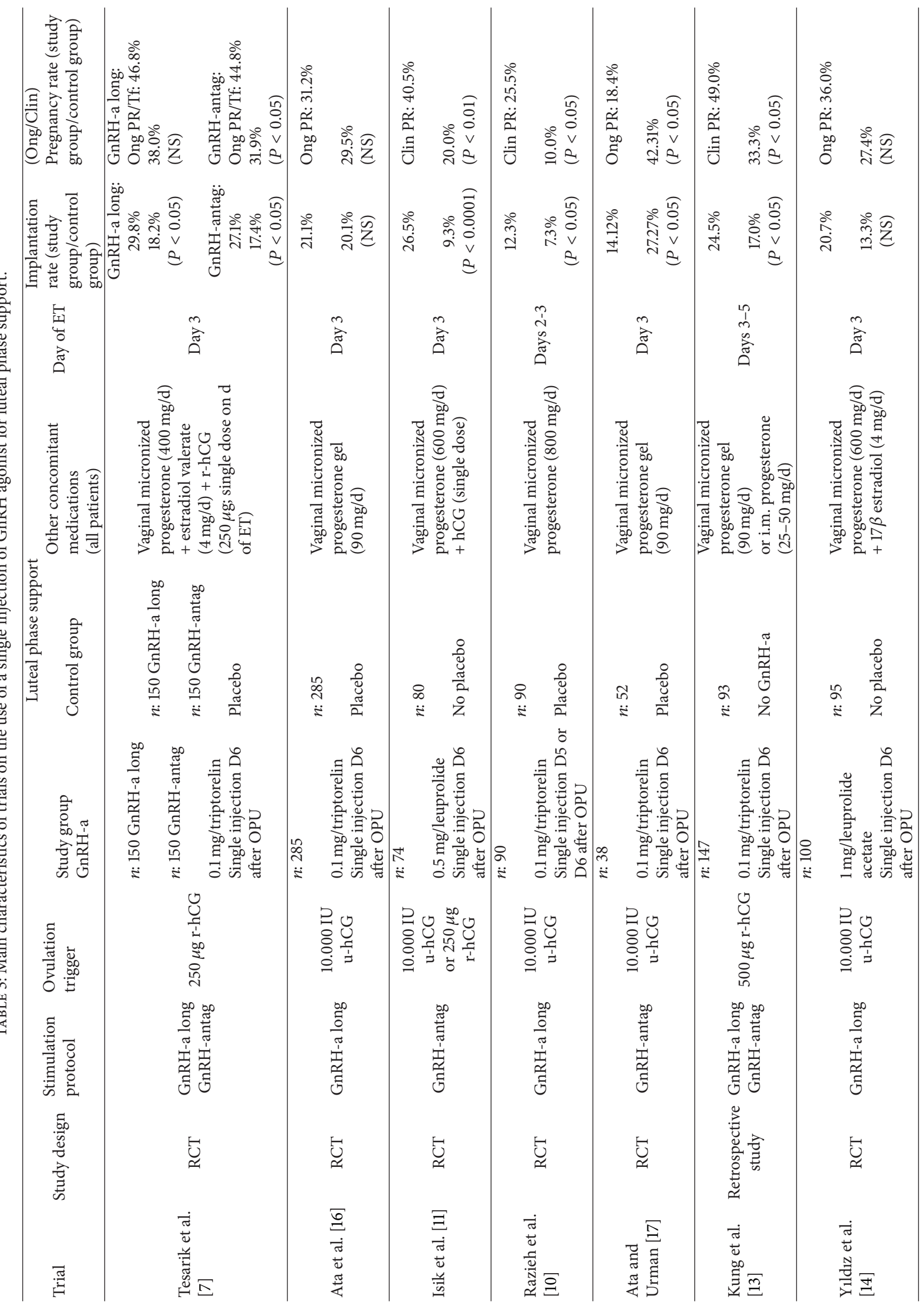




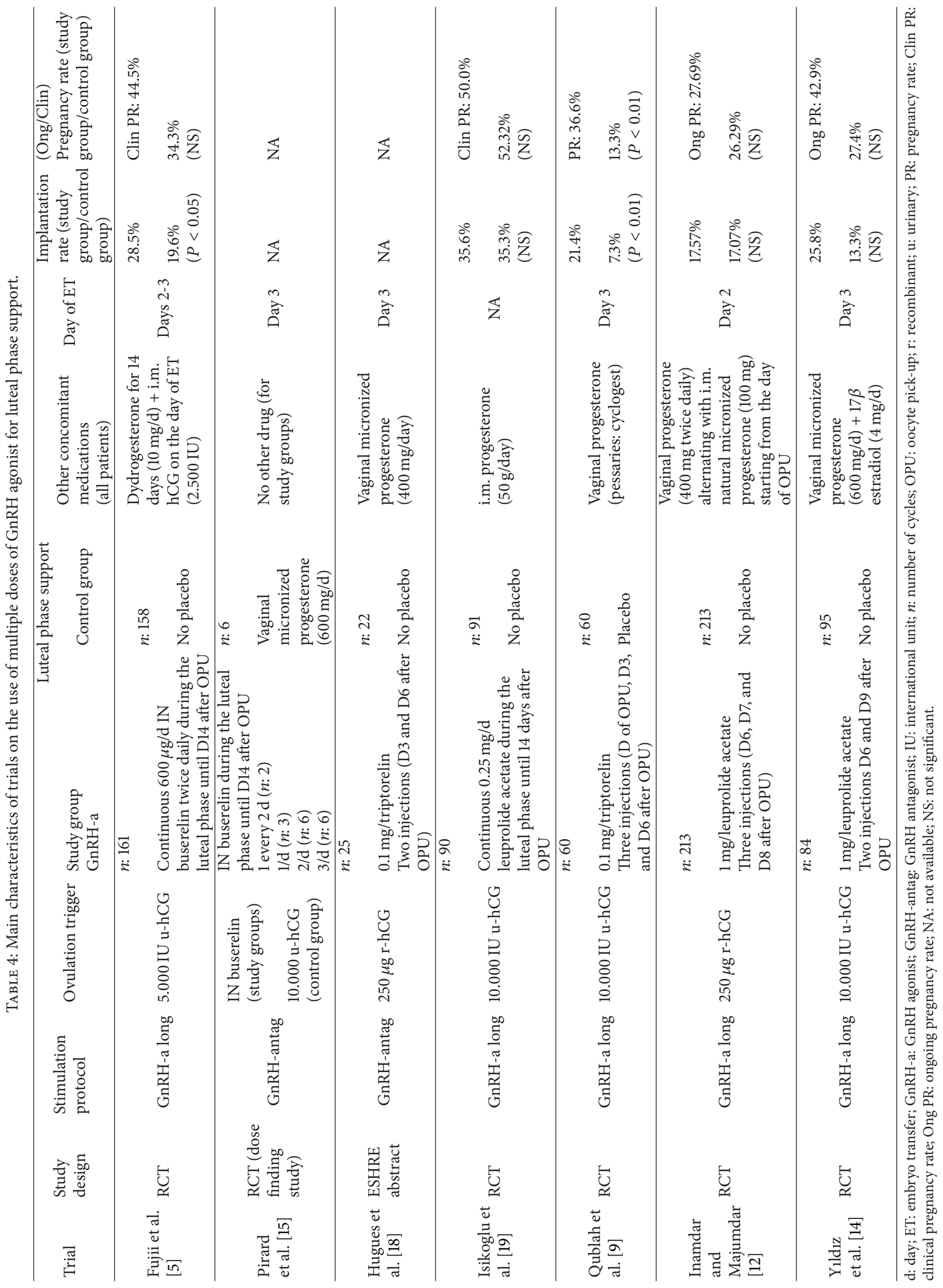


this new protocol can contribute to more patient-friendly ART.

However, although all babies born in this study were in good health, our data need to be corroborated by larger series, and caution should still be exercised concerning the condition and state of health of children issuing from this protocol.

\section{Conflict of Interests}

The authors declare that there is no conflict of interests regarding the publication of this paper.

\section{Acknowledgments}

The authors are grateful to Mira Hryniuk, B.A., for reviewing the English language of the paper. The authors thank Laurence Beausaert, their data manager, Catherine Rousseau, their head nurse, Dominique Demylle, the biologist in charge of the IVF laboratory, and their teams for their contribution to this study.

\section{References}

[1] N. S. Macklon and B. C. Fauser, "Impact of ovarian hyperstimulation on the luteal phase," Journal of reproduction and fertility. Supplement, vol. 55, pp. 101-108, 2000.

[2] E. A. Pritts and A. K. Atwood, "Luteal phase support in infertility treatment: a meta-analysis of the randomized trials," Human Reproduction, vol. 17, no. 9, pp. 2287-2299, 2002.

[3] J. Smitz, M. Camus, P. Devroey, N. Bollen, H. Tournaye, and A. C. van Steirteghem, "The influence of inadvertent intranasal buserelin administration in early pregnancy," Human Reproduction, vol. 6, no. 2, pp. 290-293, 1991.

[4] M. van der Linden, K. Buckingham, C. Farquhar, J. A. Kremer, and M. Metwally, "Luteal phase support for assisted reproduction cycles," Cochrane Database of Systematic Reviews, no. 10, Article ID CD009154, 2011.

[5] S. Fujii, S. Sato, A. Fukui, H. Kimura, G. Kasai, and Y. Saito, "Continuous administration of gonadotrophin-releasing hormone agonist during the luteal phase in IVF," Human Reproduction, vol. 16, no. 8, pp. 1671-1675, 2001.

[6] J. Tesarik, A. Hazout, and C. Mendoza, "Enhancement of embryo developmental potential by a single administration of GnRH agonist at the time of implantation," Human Reproduction, vol. 19, no. 5, pp. 1176-1180, 2004.

[7] J. Tesarik, A. Hazout, R. Mendoza-Tesarik, N. Mendoza, and C. Mendoza, "Beneficial effect of luteal-phase GnRH agonist administration on embryo implantation after ICSI in both $\mathrm{GnRH}$ agonist- and antagonist-treated ovarian stimulation cycles," Human Reproduction, vol. 21, no. 10, pp. 2572-2579, 2006.

[8] C. B. Lambalk and R. Homburg, "GnRH agonist for luteal support in IVF? Setting the balance between enthusiasm and caution," Human Reproduction, vol. 21, no. 10, pp. 2580-2582, 2006.

[9] H. Qublah, Z. Amarin, M. Al-Quda et al., "Luteal phase support with GnRH-a improves implantation and pregnancy rates in IVF cycles with endometrium of $\leq 7 \mathrm{~mm}$ on day of egg retrieval," Human Fertility (Camb), vol. 11, no. 1, pp. 43-47, 2008.
[10] D. F. Razieh, A. R. Maryam, and T. Nasim, "Beneficial effect of luteal-phase gonadotropin-releasing hormone agonist administration on implantation rate after intracytoplasmic sperm injection," Taiwanese Journal of Obstetrics and Gynecology, vol. 48 , no. 3, pp. 245-248, 2009.

[11] A. Z. Isik, G. S. Caglar, E. Sozen et al., "Single-dose GnRH agonist administration in the luteal phase of GnRH antagonist cycles: a prospective randomized study," Reproductive BioMedicine Online, vol. 19, no. 4, pp. 472-477, 2009.

[12] D. B. Inamdar and A. Majumdar, "Evaluation of the impact of gonadotropin-releasing hormone agonist as an adjuvant in luteal-phase support on IVF outcome," Journal of Human Reproductive Sciences, vol. 5, no. 3, pp. 279-284, 2012.

[13] H. F. Kung, M. J. Chen, H. F. Guua et al., "Luteal phase support with decapeptyl improves pregnancy outcomes in intracytoplasmic sperm injection with higher basal folliclestimulating hormone or lower mature oocytes," Journal of the Chinese Medical Association, vol. 77, no. 10, pp. 524-530, 2014.

[14] G. A. Yıldız, Y. E. Şükür, C. Ateş, and R. Aytaç, “The addition of gonadotrophin releasing hormone agonist to routine luteal phase support in intracytoplasmic sperm injection and embryo transfer cycles: a randomized clinical trial," European Journal of Obstetrics \& Gynecology and Reproductive Biology, vol. 182, pp. 66-70, 2014.

[15] C. Pirard, J. Donnez, and E. Loumaye, "GnRH agonist as luteal phase support in assisted reproduction technique cycles: results of a pilot study," Human Reproduction, vol. 21, no. 7, pp. 1894$1900,2006$.

[16] B. Ata, K. Yakin, B. Balaban, and B. Urman, "GnRH agonist protocol administration in the luteal phase in ICSI-ET cycles stimulated with the long GnRH agonist protocol: a randomized, controlled double blind study," Human Reproduction, vol. 23, no. 3, pp. 668-673, 2008.

[17] B. Ata and B. Urman, "Single dose GnRH agonist administration in the luteal phase of assisted reproduction cycles: is the effect dependent on the type of GnRH analogue used for pituitary suppression?" Reproductive BioMedicine Online, vol. 20, no. 1, pp. 165-166, 2010.

[18] JN. Hugues, I. Cedrin-Durnerin, B. Bsandig et al., "Administration of gonadotropin-releasing hormone agonist during the luteal phase of GnRH-antagonist IVF cycles," Human Reproduction, vol. 21, article i3, 2006.

[19] M. Isikoglu, K. Ozgur, and S. Oehninger, "Extension of GnRH agonist through the luteal phase to improve the outcome of intracytoplasmic sperm injection," Journal of Reproductive Medicine for the Obstetrician and Gynecologist, vol. 52, no. 7, pp. 639-644, 2007.

[20] S. S. Yen and R. B. Jaffe, Eds., Reproductive Endocrinology, WB Saunders, Philadelphia, Pa, USA, 1991.

[21] A. Tavaniotou, C. Albano, J. Smitz, and P. Devroey, "Impact of ovarian stimulation on corpus luteum function and embryonic implantation," Journal of Reproductive Immunology, vol. 55, no. 1-2, pp. 123-130, 2002.

[22] A. Tavaniotou, C. Albano, J. Smitz, and P. Devroey, "Effect of clomiphene citrate on follicular and luteal phase luteinizing hormone concentrations in in vitro fertilization cycles stimulated with gonadotropins and gonadotropin-releasing hormone antagonist," Fertility and Sterility, vol. 77, no. 4, pp. 733-737, 2002. 
[23] N. G. M. Beckers, N. S. Macklon, M. J. Eijkemans et al., "Nonsupplemented luteal phase characteristics after the administration of recombinant human chorionic gonadotropin, recombinant luteinizing hormone, or gonadotropin-releasing hormone $(\mathrm{GnRH})$ agonist to induce final oocyte maturation in in vitro fertilization patients after ovarian stimulation with recombinant follicle-stimulating hormone and gnrh antagonist cotreatment," The Journal of Clinical Endocrinology \& Metabolism, vol. 88, no. 9, pp. 4186-4192, 2003.

[24] C. Albano, J. Smitz, H. Tournaye, H. Riethmüller-Winzen, A. Van Steirteghem, and P. Devroey, "Luteal phase and clinical outcome after human menopausal gonadotrophin/gonadotrophin releasing hormone antagonist treatment for ovarian stimulation in in-vitro fertilization/intracytoplasmic sperm injection cycles," Human Reproduction, vol. 14, no. 6, pp. 1426-1430, 1999.

[25] J. Smitz, C. Bourgain, L. van Waesberghe, M. Camus, P. Devroey, and A. C. van Steirteghem, "A prospective randomized study on oestradiol valerate supplementation in addition to intravaginal micronized progesterone in buserelin and HMG induced superovulation," Human Reproduction, vol. 8, no. 1, pp. 40-45, 1993.

[26] P. Humaidan, H. E. Bredkjær, L. G. Westergaard, and C. Y. Andersen, "1,500 IU human chorionic gonadotropin administered at oocyte retrieval rescues the luteal phase when gonadotropin-releasing hormone agonist is used for ovulation induction: a prospective, randomized, controlled study," Fertility and Sterility, vol. 93, no. 3, pp. 847-854, 2010.

[27] J. C. Castillo, M. Dolz, E. Bienvenido, L. Abad, E. M. Casan, and F. Bonilla-Musoles, "Cycles triggered with GnRH agonist: exploring low-dose HCG for luteal support," Reproductive BioMedicine Online, vol. 20, no. 2, pp. 175-181, 2010.

[28] B. Radesic and K. Tremellen, "Oocyte maturation employing a GnRH agonist in combination with low-dose hCG luteal rescue minimizes the severity of ovarian hyperstimulation syndrome while maintaining excellent pregnancy rates," Human Reproduction, vol. 26, no. 12, pp. 3437-3442, 2011.

[29] S. Kol, P. Humaidan, and J. Itskovitz-Eldor, "GnRH agonist ovulation trigger and hCG-based, progesterone-free luteal support: a proof of concept study," Human Reproduction, vol. 26, no. 10, pp. 2874-2877, 2011.

[30] S. Iliodromiti, V. T. N. Lan, H. M. Tuong, P. H. Tuan, P. Humaidan, and S. M. Nelson, "Impact of GnRH agonist triggering and intensive luteal steroid support on live-birth rates and ovarian hyperstimulation syndrome: a retrospective cohort study," Journal of Ovarian Research, vol. 6, no. 1, article 93, 2013.

[31] P. Humaidan, L. H. Thomsen, and B. Alsbjerg, "GnRHa trigger and modified luteal support with one bolus of hCG should be used with caution in extreme responder patients," Human Reproduction, vol. 28, no. 9, pp. 2593-2594, 2013.

[32] E. G. Papanikolaou, W. Verpoest, H. Fatemi, B. Tarlatzis, P. Devroey, and H. Tournaye, "A novel method of luteal supplementation with recombinant luteinizing hormone when a gonadotropin-releasing hormone agonist is used instead of human chorionic gonadotropin for ovulation triggering: a randomized prospective proof of concept study," Fertility and Sterility, vol. 95, no. 3, pp. 1174-1177, 2011.

[33] L. Engmann, A. DiLuigi, D. Schmidt, C. Benadiva, D. Maier, and J. Nulsen, "The effect of luteal phase vaginal estradiol supplementation on the success of in vitro fertilization treatment: a prospective randomized study," Fertility and Sterility, vol. 89, no. 3, pp. 554-561, 2008.

[34] B. S. Shapiro, S. T. Daneshmand, F. C. Garner, M. Aguirre, and C. Hudson, "Comparison of 'triggers' using leuprolide acetate alone or in combination with low-dose human chorionic gonadotropin," Fertility and Sterility, vol. 95, no. 8, pp. 27152717, 2011.

[35] R. Orvieto, "Intensive luteal-phase support with oestradiol and progesterone after GnRH-agonist triggering: does it help?" Reproductive BioMedicine Online, vol. 24, no. 6, pp. 680-681, 2012.

[36] J. Balasch, F. Martinez, I. Jove et al., "Inadvertent gonadotrophin-releasing hormone agonist (GnRHa) administration in the luteal phase may improve fecundity in in-vitro fertilization patients," Human Reproduction, vol. 8, no. 7, pp. 1148-1151, 1993.

[37] P. Humaidan, H. E. Bredkjær, L. Bungum et al., "GnRH agonist (buserelin) or hCG for ovulation induction in GnRH antagonist IVF/ICSI cycles: a prospective randomized study," Human Reproduction, vol. 20, no. 5, pp. 1213-1220, 2005.

[38] E. M. Kolibianakis, A. Schultze-Mosgau, A. Schroer et al., "A lower ongoing pregnancy rate can be expected when $\mathrm{GnRH}$ agonist is used for triggering final oocyte maturation instead of HCG in patients undergoing IVF with GnRH antagonists," Human Reproduction, vol. 20, no. 10, pp. 2887-2892, 2005.

[39] M. A. Youssef, F. Van der Veen, H. G. Al-Inany et al., "Gonadotropin-releasing hormone agonist versus HCG for oocyte triggering in antagonist assisted reproductive technology cycles," Cochrane Database of Systematic Reviews, no. 11, Article ID CD008046, 2011.

[40] B. Acevedo, J. L. Gomez-Palomares, E. Ricciarelli, and E. R. Hernández, "Triggering ovulation with gonadotropin-releasing hormone agonists does not compromise embryo implantation rates," Fertility and Sterility, vol. 86, no. 6, pp. 1682-1687, 2006.

[41] G. Griesinger, E. M. Kolibianakis, E. G. Papanikolaou et al., "Triggering of final oocyte maturation with gonadotropinreleasing hormone agonist or human chorionic gonadotropin. Live birth after frozen-thawed embryo replacement cycles," Fertility and Sterility, vol. 88, no. 3, pp. 616-621, 2007.

[42] E. M. Casañ, F. Raga, and M. L. Polan, "GnRH mRNA and protein expression in human preimplantation embryos," Molecular Human Reproduction, vol. 5, no. 3, pp. 234-239, 1999.

[43] E. M. Casañ, F. Raga, F. Bonilla-Musoles, and M. L. Polan, "Human oviductal gonadotropin-releasing hormone: possible implications in fertilization, early embryonic development, and implantation," The Journal of Clinical Endocrinology \& Metabolism, vol. 85, no. 4, pp. 1377-1381, 2000.

[44] F. Raga, E. M. Casañ, J. Kruesse, Y. Wen, F. Bonilla-Musoles, and M. L. Polan, "The role of gonadotropin-releasing hormone in murine preimplantation embryonic development," Endocrinology, vol. 140, no. 8, pp. 3705-3712, 1999.

[45] K. Kawamura, J. Fukuda, J. Kumagai et al., "Gonadotropinreleasing hormone I analog acts as an anti-apoptotic factor in mouse blastocysts," Endocrinology, vol. 146, no. 9, pp. 4105-4116, 2005.

[46] D. H. Nam, S. H. Lee, H. S. Kim et al., "The role of gonadotropinreleasing hormone $(\mathrm{GnRH})$ and its receptor in development of porcine preimplantation embryos derived from in vitro fertilization," Theriogenology, vol. 63, no. 1, pp. 190-201, 2005.

[47] L.-S. Lin, V. J. Roberts, and S. S. Yen, "Expression of human gonadotropin-releasing hormone receptor gene in the placenta and its functional relationship to human chorionic gonadotropin secretion," Journal of Clinical Endocrinology and Metabolism, vol. 80, no. 2, pp. 580-585, 1995.

[48] D. Islami, D. Chardonnens, A. Campana, and P. Bischof, "Comparison of the effects of GnRH-I and GnRH-II on HCG 
synthesis and secretion by first trimester trophoblast," Molecular Human Reproduction, vol. 7, no. 1, pp. 3-9, 2001.

[49] F. Raga, E. M. Casañ, J. S. Kruessel et al., “Quantitative gonadotropin-releasing hormone gene expression and immunohistochemical localization in human endometrium throughout the menstrual cycle," Biology of Reproduction, vol. 59, no. 3, pp. 661669, 1998.

[50] M. Shemesh, "Actions of gonadotrophins on the uterus," Reproduction, vol. 121, no. 6, pp. 835-842, 2001.

[51] P. A. B. Klemmt, F. Liu, J. G. Carver et al., "Effects of gonadotrophin releasing hormone analogues on human endometrial stromal cells and embryo invasion in vitro," Human Reproduction, vol. 24, no. 9, pp. 2187-2192, 2009.

[52] J. B. A. Oliveira, R. Baruffi, C. G. Petersen, A. L. Mauri, M. Cavagna, and J. G. Franco Jr., "Administration of single-dose GnRH agonist in the luteal phase in ICSI cycles: a metaanalysis," Reproductive Biology and Endocrinology, vol. 8, article 107, 2010.

[53] E. A. Stewart, "Gonadotropins and the uterus: is there a gonadindependent pathway?" Journal of the Society for Gynecologic Investigation, vol. 8, no. 6, pp. 319-326, 2001.

[54] C. V. Rao and Z. M. Lei, "Consequences of targeted inactivation of LH receptors," Molecular and Cellular Endocrinology, vol. 187, no. 1-2, pp. 57-67, 2002.

[55] J. Tesarik, A. Hazout, and C. Mendoza, "Luteinizing hormone affects uterine receptivity independently of ovarian function," Reproductive BioMedicine Online, vol. 7, no. 1, pp. 59-64, 2003.

[56] E. Loumaye, S. Depreester, J. Donnez, and K. Thomas, "Immunoreactive relaxin surge in the peritoneal fluid of women during the midluteal phase," Fertility and Sterility, vol. 42, no. 6, pp. 856-860, 1984.

[57] P. Licht, V. Russu, and L. Wildt, "On the role of human chorionic gonadotropin (hCG) in the embryo-endometrial microenvironment: Implications for differentiation and implantation," Seminars in Reproductive Medicine, vol. 19, no. 1, pp. 37-47, 2001. 


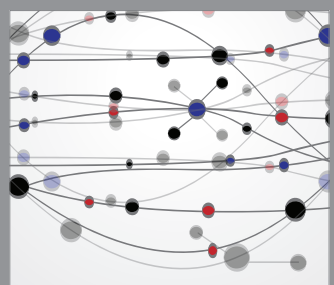

The Scientific World Journal
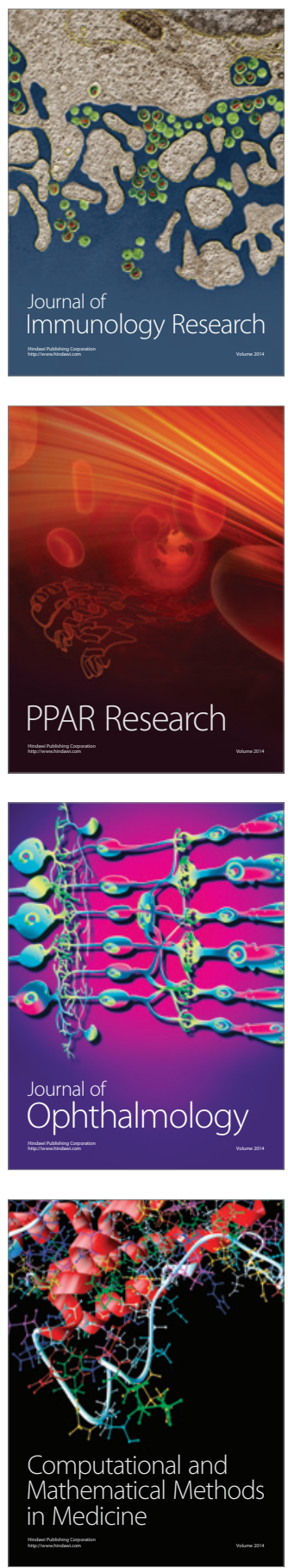

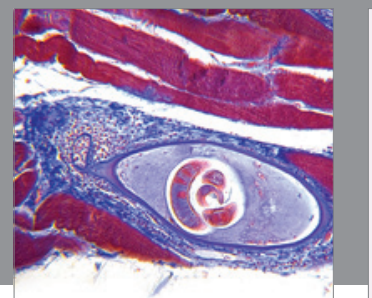

Gastroenterology

Research and Practice
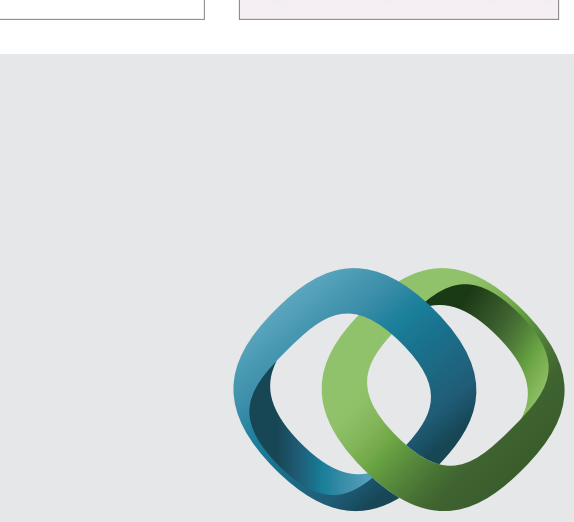

\section{Hindawi}

Submit your manuscripts at

http://www.hindawi.com
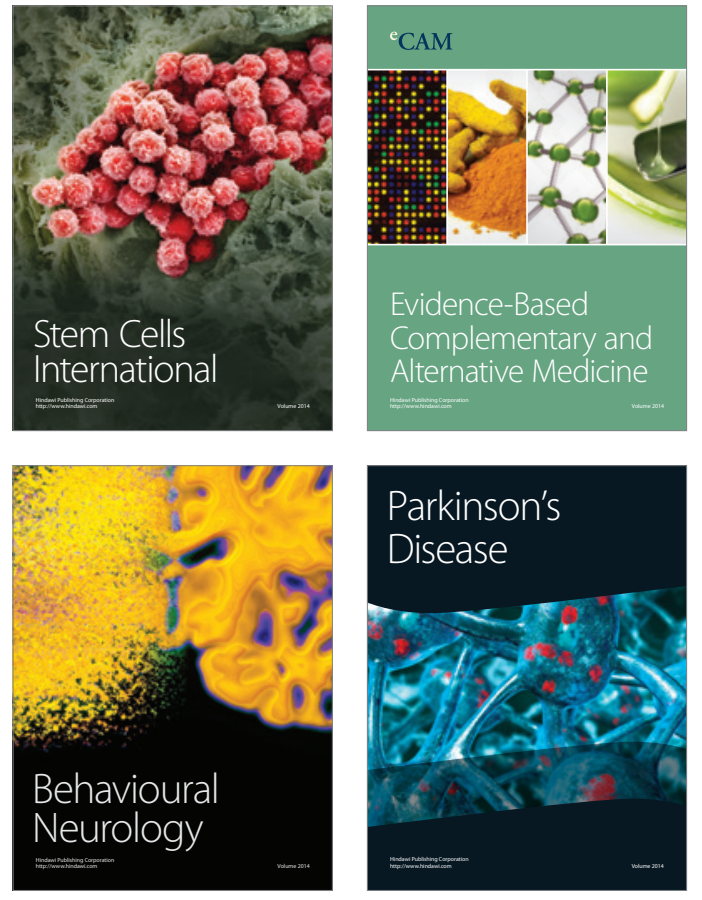
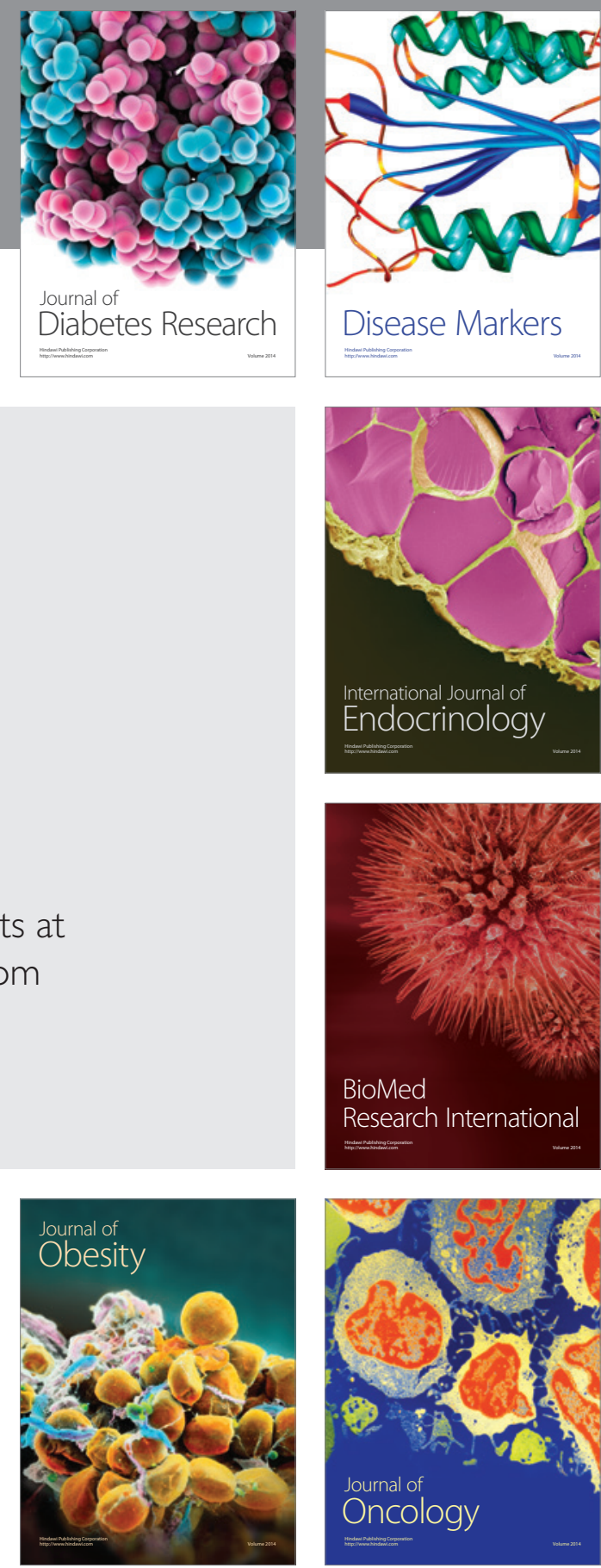

Disease Markers
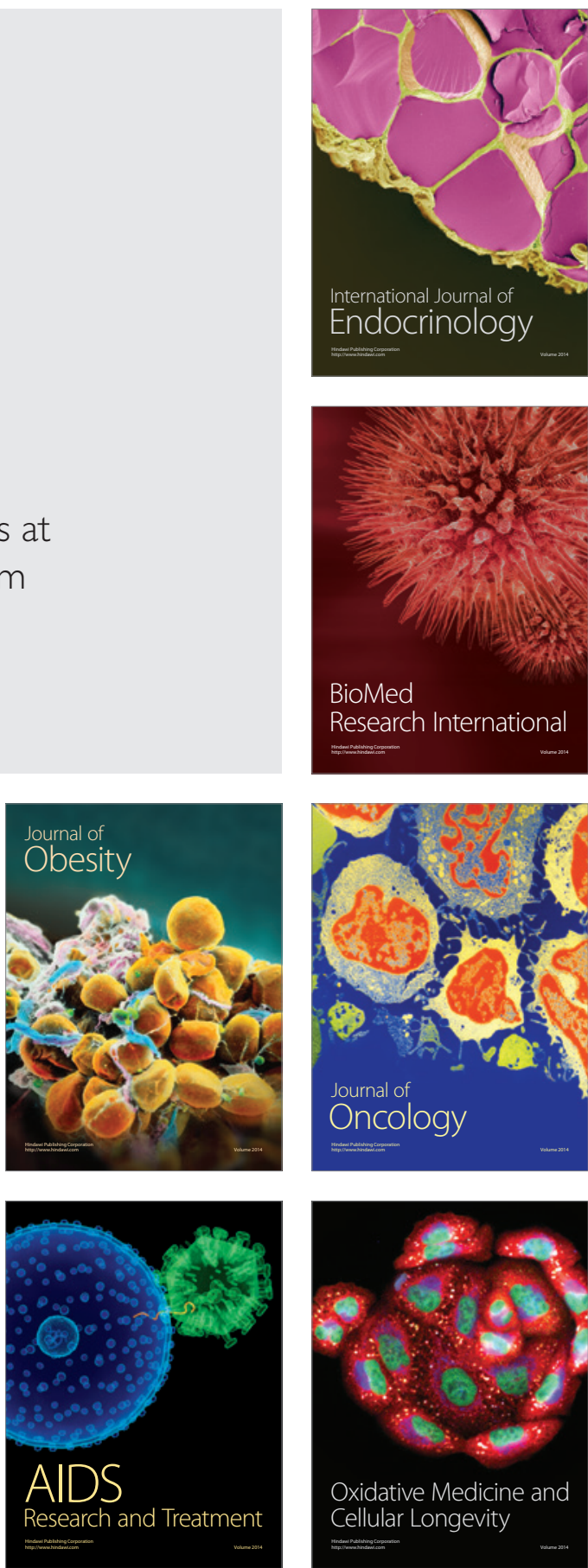